\title{
Scientific reasoning ability does not predict scientific views on evolution among religious individuals
}

\author{
Katie F. Manwaring ${ }^{1}$, Jamie L. Jensen ${ }^{1 *} \mathbb{0}$, Richard A. Gill', Richard R. Sudweeks' ${ }^{2}$, Randall S. Davies² \\ and Seth M. Bybee ${ }^{1}$
}

\begin{abstract}
Background: Acceptance of evolutionary theory varies widely and is often associated with religious background. Some have suggested there exists an additional relationship between scientific reasoning ability and the acceptance of evolutionary theory. In this study, we used structural equation modeling to test whether scientific reasoning ability predicts religiosity, acceptance of creationist views, or acceptance of evolution. We administered internet-based surveys to 724 individuals nationwide who self-describe as being religious and built a structural-equation model to test predictive abilities.

Results: We found that while religiosity positively predicts the acceptance of creationist views and negatively predicts the acceptance of evolution, scientific reasoning ability does not predict religiosity, acceptance of creationist views, or acceptance of evolutionary theory.

Conclusions: With a lack of any relationship between scientific reasoning ability and acceptance, an approach to evolution education that focuses on appealing to scientific reasoning may prove fruitless in changing student attitudes toward evolution; alternative teaching approaches regarding evolution are warranted.
\end{abstract}

Keywords: Macroevolution, Science education, Scientific reasoning, Religiosity, Creationism

\section{Background}

Darwin's publication of The Origin of Species (Darwin 1859) marked the founding of the mechanisms that underpin evolutionary theory. The Modern Synthesis has since reformed this theory to include the principles of natural selection combined with Mendelian genetics and population-level thinking (Mayr 1982; Provine 1971). Dobzhansky's famous statement about the importance of evolution (Dobzhansky 1973) reiterates the foundational nature of this theory in modern biology. Since Darwin, decades of scientific work have supported the validity of evolutionary theory (e.g., Daeschler et al. 2006; Dobzhansky and Pavlovsky 1957; Grant and Grant 2002; Haldane 1957; Ostrom 1976; Theobald 2010). Despite the

\footnotetext{
*Correspondence: Jamie.Jensen@byu.edu

1 Department of Biology, 4102 LSB, Brigham Young University, Provo, UT 84602, USA

Full list of author information is available at the end of the article
}

overwhelming evidence, in a Pew 2008 poll (Pew 2008) nearly half of American adults rejected the claim that evolution provides the best explanation for life on earth. In polls spanning from 2009 to 2014 regarding human evolution, $31-34 \%$ of US adults still believe that humans were created in their present form from the beginning, and this rate has stayed fairly constant over this time period (Pew 2015). In 2017, Gallup reported that 38\% of Americans hold a creationist view of human origins (Gallup 2017).

Religious views, while an integral part of our cultural richness, have been negatively associated with the acceptance of evolution in several studies (Anderson 2007; Andersson and Wallin 2006) and a poorer understanding of the physical world (Lindeman and Svedholm-Häkkinen 2016). For individuals who have a strong religious background, science instructors may face difficulty overcoming these barriers using existing 
pedagogical approaches. Studies have shown that highly religious students are less likely to both understand and accept evolution (Barnes et al. 2009; Moore et al. 2011). In a survey of thirty-four countries across the world, the United States has the second to lowest evolution acceptance rate (Miller et al. 2006), a likely result of a highly religious population (Coyne 2012) and perhaps a result of the structure of the American educational system such that no central organization exists, allowing for creationism to be taught in the schools (Branch et al. 2010; Plutzer and Berkman 2008).

An individual's religiosity, defined as the level of commitment to religious practices and principles centered on a belief in God (Cornwall et al. 1986), has also been shown to be negatively correlated with acceptance (Heddy and Nadelson 2013). The same trend was observed among both small and large study populations (Alters and Alters 2001; Heddy and Nadelson 2013; Miller et al. 2006; Nadelson and Sinatra 2010; Scott 2005; Rissler et al. 2014; Rutledge and Sadler 2007). Religiosity can be measured through behaviors such as church attendance and frequency of prayer (religious practices), influence of religion on daily decisions on things such as food choice or clothing (religious influence), and outlook on life/future (religious hope. Researchers have repeatedly found a negative correlation between religiosity and evolution acceptance (e.g., Coyne 2012; Heddy and Nadelson 2013; Manwaring et al. 2015). However, the degree to which religious people embrace creationism (i.e., a belief in a divinely influenced creation of the universe and all living organisms) is extremely variable, ranging from belief in a young earth (e.g., a creation that took place in 6000 years) and special creation (i.e., a literal interpretation of the bible), to a belief in theistic evolution (i.e., evolution guided by a supreme being) (see Pew 2015). Where an individual lies on the spectrum of creationism usually defines where they fall on the spectrum of evolution acceptance (Scott 1997).

Another factor that has been suggested to play a role in evolution acceptance is scientific reasoning ability. Scientific reasoning ability is defined as the ability to demonstrate the patterns of formal operations including proportional reasoning, identifying and controlling variables, probabilistic reasoning, correlational reasoning, combinatorial reasoning, and hypothetico-deductive reasoning (Lawson 1982). Scientific reasoning ability has been shown to be the strongest predictor of science achievement in several studies (Johnson and Lawson 1998; Lawson et al. 2007, 2000). A well-used tool for measuring scientific reasoning ability is Lawson's Classroom Test of Scientific Reasoning (LCTSR; Lawson 1978, ver. 2000). This tool has been used in a variety of studies for multiple purposes including to test Piaget's cognitive development theory (Lin 1980; Niaz 1991), to compare scientific reasoning ability with knowledge acquisition (Bao et al. 2009; Lawson and Thompson 1988; Gerber et al. 1996), to diagnose learning ability for various ages and educational groups (Lawson et al. 2007; Lawson and Worsnop 1992), and to research gender differences (Shemesh 1990; Germann 1994). Lawson and Worsnop (1992) have suggested that high religiosity is correlated with low scientific reasoning skills (the direction of the relationship between these two being unclear) and that these reduced reasoning skills lead to reduced acceptance of evolution. The implication is that religiosity and a belief in divine creation may act as obstacles between reasoning ability and acceptance of evolution. Despite the abundance of literature on scientific reasoning ability and its influence on learning (e.g., Bao et al. 2009; Carmel and Yezierski 2013; Gormally et al. 2012; Jensen et al. 2015; Lawson et al. 2007; She and Liao 2010; Zimmerman 2000), a relationship between scientific reasoning ability and the learning and acceptance of evolutionary theory remains unclear (e.g., Deniz et al. 2008; Hokayem and BouJaoude 2008; Nehm and Schonfeld 2007).

We sought to test the hypothesis that scientific reasoning ability influences both religiosity and an acceptance of evolution. This hypothesis was influenced by two studies (Lawson and Worsnop 1992; Lawson and Weser 1990) in which researchers measured the relationships between scientific reasoning ability and non-scientific views, religiosity, and knowledge of evolution. They measured students' scientific reasoning ability using the Lawson Classroom Test of Scientific Reasoning (LCTSR; Lawson 1978), and students' strength of religious commitment, declarative knowledge of evolution, belief in special creation, and acceptance of evolution using researchercreated survey instruments. Their main hypothesis was that higher levels of scientific reasoning ability led to a rejection of non-scientific views and an acceptance of evolution. Combining the two studies, three main trends emerged: (1) religious commitment contributes positively to a belief in special creation and negatively to acceptance of evolution, (2) students with higher levels of scientific reasoning ability are less likely to accept non-scientific beliefs, and (3) having higher levels of scientific reasoning ability correlates with greater gains in knowledge about science (Lawson and Worsnop 1992; Lawson and Weser 1990). Although it was implied that levels of scientific reasoning ability and religiosity were inversely related in a path analysis (Lawson and Worsnop 1992), the relationship was not significant. Our goal in this current study was to test whether one's level of scientific reasoning ability predicts religiosity, acceptance of creationist views, and acceptance of evolution. We used structural equation modeling, a robust analysis method that can account 
for connections between multiple variables simultaneously (Muthén and Muthén 1998-2010). In addition, we validated and established reliability of our independent measures through statistical techniques to increase the validity of our findings.

\section{Methods}

\section{Ethics statement}

Permission for research with human subjects was acquired through the Institutional Review Board of the primary author's institution. Implied consent was received from all participants.

\section{Participants}

Using internet-based survey instruments distributed by Qualtrics, LLC (2016), we surveyed 724 religious individuals across the US, from four major US religious groups: Protestant, Catholic, Mormon, and Jewish (including all sects of Judaism (Religious landscape study 2017). Qualtrics contracts with the European Society for Opinion and Marketing Research (ESOMAR) to recruit representative nationwide and worldwide panels for any set of criteria specified by the researcher (for more information about panel recruitment, see 28 Questions to help buyers of online samples 2017). Participants were chosen on the basis of self-identified membership to one of four specific religions: Catholicism, Judaism, The Church of Jesus Christ of Latter-day Saints (i.e., Mormonism), or the Southern Baptist Convention (representing one branch of Protestantism). The level of religiosity among those surveyed varied widely (Range: $15-89$ on a 90-point scale; $M=51.63, S D=15.48) .57 \%$ of the individuals surveyed were between 18 and 25 years old. Our target population was individuals who have identified with a religion; thus we did not include irreligious (i.e., atheist or agnostic or anyone who did not identify with one of the four religious groups) individuals in the sample. Two reasons guided this choice: (1) our research goal was to determine whether a relationship exists between scientific reasoning ability, levels of religiosity, and acceptance of evolution amongst religious individuals, and (2) key survey instruments were designed for and validated with a religious audience (see Sethi and Seligman 1993) and thus may be unreliable or invalid among non-religious individuals (e.g., How much influence do your religious beliefs have on what you wear?).

\section{Instruments}

We used four surveys that assessed subjects' scientific reasoning ability, religiosity, acceptance of creationist views, and acceptance of evolution. All instruments were administered as a single combined survey. A description of each instrument designed for the current study is provided below (full survey instruments are available in the Additional file 1: Instruments S1.).

1. Measure of Religiosity: This previously published instrument measures levels of religiosity, specifically religious influence in daily life, religious involvement, and religious hope (Sethi and Seligman 1993). In this study, it was used to determine the relationship between religiosity and scientific reasoning ability, creationist views, and acceptance of evolution. Responders were asked questions regarding the frequency of their religious practices, the influence religion has on their lifestyles, and their outlook on life. We added one item about religious commitment to the survey (included below). This composite measure was comprised of 15 items with six response categories on a Likert response scale (i.e., strongly disagree to strongly agree). Item responses were summed to produce a total religiosity score. The scale had a high level of internal consistency within our sample, as determined by a Cronbach's alpha of 914 .

2. Measure of Creationist Views. We designed these questions specifically for this study. Our goal was to measure the literalist nature of views on the creation, including the nature of God, age of the earth, fixity of species, and the origin of humans. This instrument contained 13 questions, with six response categories on a Likert response scale. Responses were averaged across items to obtain a composite score. Higher scores represented strong religious creationist views. As a pilot, this survey was administered to 585 individuals recruited through social media and 73 individuals recruited at the authors' institution. Validity and reliability tests demonstrated the instrument measured a single factor (via confirmatory factor analysis) and had a high level of internal consistency with a Cronbach's alpha score of 955.

3. Measure of Attitude toward Evolution: We designed these questions as a measure of our dependent variable-acceptance of evolution. It was patterned after the Measurement of Acceptance of the Theory of Evolution (MATE) (Rutledge and Sadler 2007) in that it had similarly structured statements, it was scored on a Likert scale, and it targeted specific aspects of evolution including the age of the earth, human evolution, and evolution as an explanation for our current biodiversity. However, we focused on our instrument only on evolution acceptance and did not include questions on the validity of science or the scientific process that are included in the MATE. We did, however, include additional items on the fixity of species, not included in the MATE. It consisted of 12 items, again with six response categories on the Lik- 
ert response scale. Responses were averaged across items to obtain a composite score. Higher scores represented stronger acceptance of evolution. This survey was piloted among the same group of individuals as the creationist views instrument. Validity and reliability tests demonstrated the instrument measured a single factor (via confirmatory factor analysis) and had a high level of internal consistency with a Cronbach's alpha score of 953 .

4. Lawson's Classroom Test of Scientific Reasoning (LCTSR; Lawson 1978, version 2000): This is a measure of scientific reasoning abilities, including proportional reasoning, identifying and controlling variables, probabilistic reasoning, correlational reasoning, and hypothetico-deductive reasoning. This instrument consists of 12 paired questions (24 items total) with multiple-choice categories. The first question in a pair solicits an answer to a problem and the second question solicits an explanation of a student's reasoning. This test was administered at the end of the survey for 600 of the responders and at the beginning for 124 responders to test for survey fatigue. There was no statistically significant difference in LCTSR scores between the two groups $[F(1723)=1.55, p=.213]$.

\section{Analyses}

We used factor analysis and Structural Equation Modeling (SEM), a robust analysis method used when examining dependencies between multiple variables simultaneously (Muthén and Muthén 1998-2010). Factor analysis was completed using Mplus software ver. 7.3. Variables analyzed in our model were total religiosity (measured by three factors: religious practices, religious influence, and religious hope), creationist views, scientific reasoning, and acceptance of evolution. The data set was split in two to create two independent data sets. An exploratory factor analysis (EFA) was performed using half the data set on each instrument, using SPSS software ver. 21, followed by confirmatory factor analyses (CFA) on the other half of the data set, using Mplus. Geomin rotation was used in the EFA and a scree plot, eigenvalues, and percentage variance explained were employed to determine how many factors to retain. Items were removed or adjusted to provide the strongest measures of each latent variable. In the CFA, fit of each instrument model to the data was analyzed via fit indices, TuckerLewis index (TLI), comparative fit index (CFI), root mean square error of approximation (RMSEA), and Chi square $\left(x^{2}\right)$ statistics. In the CFA and measurement model for each instrument, variables were classified as categorical to activate a weighted least squares estimator (WLSMV). All instruments were combined into a full measurement model to ensure fit of model to the data prior to structural modeling.

After the measurement model was analyzed and a good fit was obtained, we examined the structural relationships among the latent variables using structural equation modeling. A hypothesized path diagram (structural model) was determined for the resulting factors and a structural model analysis was run in Mplus. The final model was selected based on fit statistics, as described below.

\section{Availability of data and materials}

Full survey instruments are available in the Additional file 1: Instruments S1. All data is available through DRYAD, accession number (to be populated at publication).

\section{Results}

Statistical results of EFA and CFA

Exploratory factor analysis (EFA)

Exploratory factor analysis rendered three factors from our religious measure with eigenvalues above 1 that explained over $5 \%$ of the variance seen in the data. The resulting religiosity factors were defined as religious practice, religious influence, and religious hope. The remaining measures, creationist views, scientific reasoning and evolution acceptance, each resulted in only one factor with an eigenvalue higher than 1 that explained more than $5 \%$ of the variance. From this, we concluded that the survey instrument measured six factors: religious practice, religious influence, religious hope, creationist views, scientific reasoning, and evolution acceptance.

\section{Confirmatory factor analysis (CFA)}

We used CFA to confirm that each instrument measured the identified factor. The following items were excluded from this analysis due to lack of fit or redundancy: one item regarding frequency of prayer (i.e., How often do you pray?) was removed from the religious practice factor due to poor fit, one item was removed from the religious hope factor due to poor fit (i.e., Do you believe it is possible for all humans to live in harmony together?), and two items were removed from the creationist views factor due to redundancy (lack of uniqueness; i.e., All creatures on earth were created in the last 10,000 years and All present day humans are direct descendants of Adam and Eve). The resulting fit statistics show that each instrument model fit the data well (see Table 1). Figure 1 displays the measurement model with correlation coefficients displayed between each factor and factor loadings shown between each item and the factor of which it is a part. The factor loadings for each item across all instruments were high (above .5) with few exceptions. One 
Table 1 Fit statistics for each instrument and measurement model

\begin{tabular}{|c|c|c|c|c|c|c|}
\hline \multirow[t]{2}{*}{ Latent variable (construct) } & \multirow[t]{2}{*}{ TLI } & \multirow[t]{2}{*}{ CFI } & \multirow[t]{2}{*}{ RMSEA } & \multicolumn{3}{|c|}{ Chi square test } \\
\hline & & & & $\overline{x^{2}}$ & DF & $p$ value \\
\hline Religiosity & .977 & .970 & .081 & 1057.233 & 481 & $<.001$ \\
\hline Scientific reasoning & .952 & .939 & .055 & 237.278 & 154 & $<.001$ \\
\hline Creationist views & .992 & .981 & .103 & 249.560 & 86 & $<.001$ \\
\hline Acceptance of evolution & .989 & .957 & .122 & 361.919 & 98 & $<.001$ \\
\hline Complete measurement model & .981 & .982 & .040 & 2284.178 & 1064 & $<.001$ \\
\hline
\end{tabular}

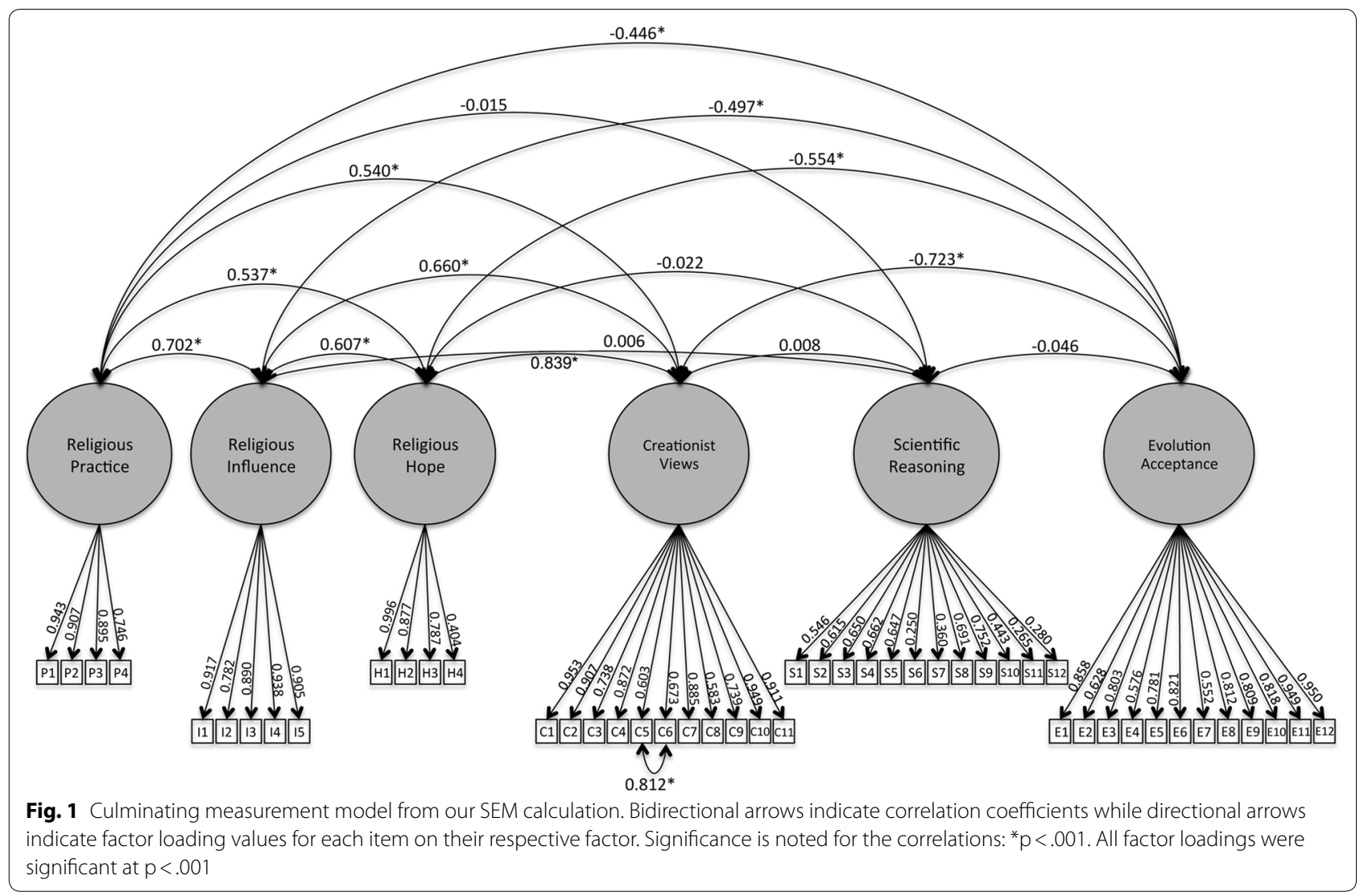

cross loading was added between items 5 and 6 for creationist views indicating an overlap in what they are measuring. From our CFA, we found that our instruments are valid in measuring distinct and identifiable factors.

\section{Results of structural equation modeling}

Using structural equation modeling, we found that scientific reasoning ability does not correlate with religiosity among religious individuals (Fig. 2). This means that religiosity does not predict scientific reasoning ability and scientific reasoning ability does not predict religiosity. Each is an independent measure uncorrelated with the other. In addition, we found that scientific reasoning ability was a non-significant predictor of acceptance of creationist views or acceptance of evolutionary theory among religious individuals $(p>.05)$. In other words, a religious individual's scientific reasoning ability plays no predictive role in their decision to accept or reject either creationist views or evolutionary theory.

The model shows that all three factors of religiosity (religious practice, religious influence, and religious hope) are strongly correlated with one another $(p<.001)$. It also shows that two components of religiosity (religious hope and religious influence) are significant positive predictors of creationist views $(p<.001)$ and that acceptance of creationist views is a significant negative predictor of 


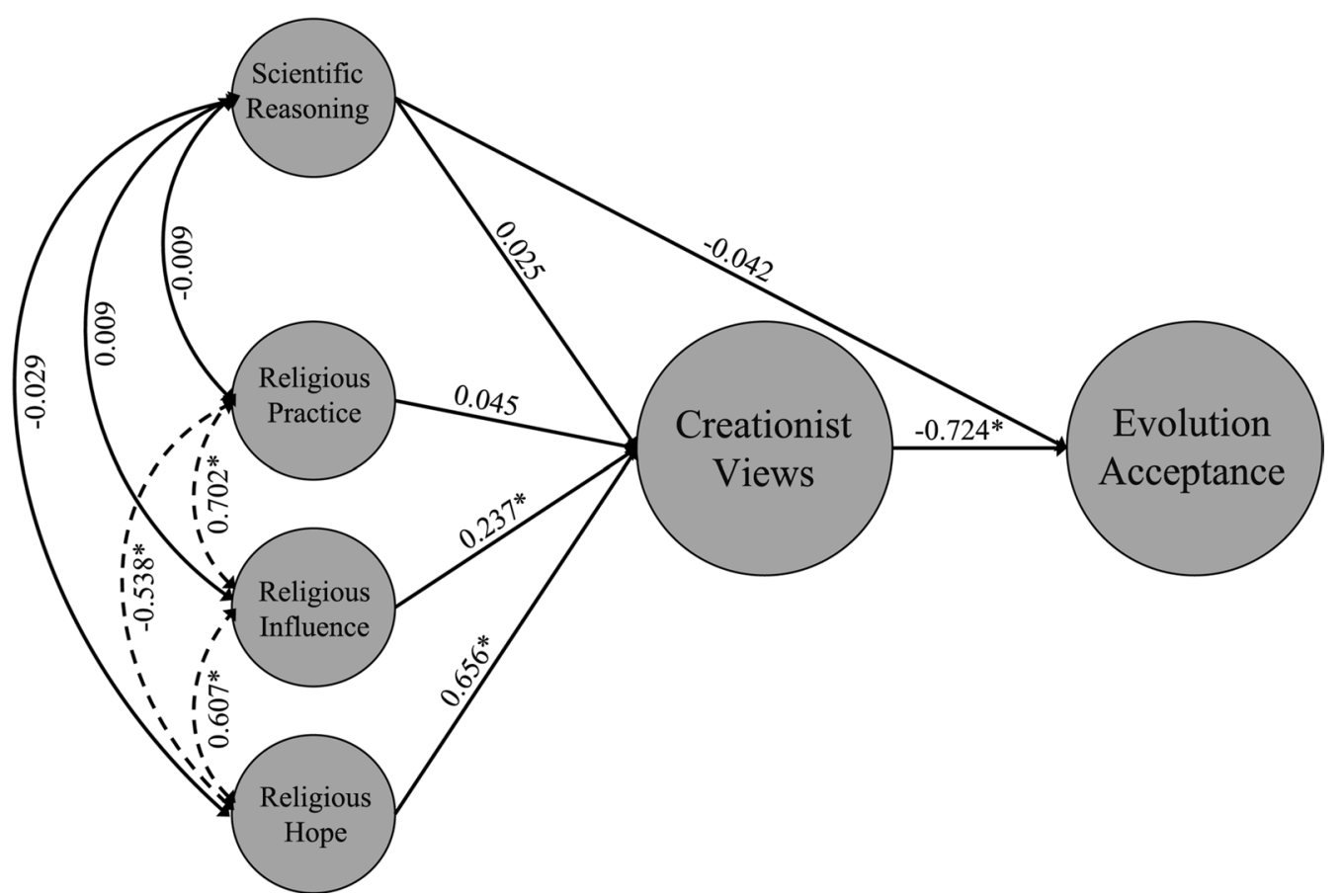

Fig. 2 Illustration of structural equation model that characterizes relationships among factors. Bidirectional lines (dotted line) indicate correlation coefficients, while directional lines (solid lines) indicate predictive relationships. Significance is noted: ${ }^{*} p<0.001$

evolution acceptance (i.e., higher religiosity and acceptance of creationist views predicts lower acceptance of evolution; $p<.001$ ). The indirect negative effect of religious hope and religious influence on acceptance of evolution is also significant $(p<.001)$. The structural model demonstrated a robust fit for the data as indicated by fit statistics and probability scores $(\mathrm{TLI}=.988 ; \mathrm{CFI}=.973$; RMSEA $\left.=.067 ; \mathrm{X}^{2}=544.647, p<.001\right)$. Further, $92.3 \%$ of parameter estimates were statistically significant.

\section{Discussion}

The data show that the ability to reason using the complex patterns of science (as measured by the LCTSR) has little or no bearing upon whether a religious person chooses to accept evolution as a well-supported scientific theory. In addition, scientific reasoning ability has no effect on the level of commitment to four major religious groups. In other words, our analysis did not reveal a causal or associative relationship between scientific reasoning ability and high religiosity or low acceptance of evolutionary theory in religious individuals, contradicting previous hypotheses (Lawson and Weser 1990). A religious individual can be well skilled in scientific reasoning and still reject evolution, perhaps on religious grounds. Certainly, abundant evidence exists in support of a negative relationship between religious affiliation or commitment and acceptance of evolution (Miller
2008; Miller et al. 2006; Drees 2012; Heddy and Nadelson 2013; Village and Baker 2013). However, an individual's scientific reasoning ability does not predict that level of commitment amongst the four religious populations we surveyed. In a study examining two cognitive approaches to belief, bounded rationality and expressive rationality, Kahan and Stanovich (2016) found that students' performance on the Cognitive Reflection Test, a measure of critical reasoning, did not correlate with acceptance of evolution, as predicted. Instead, it was more likely that students formed beliefs congruent with their cultural identities, which may include religious beliefs.

Others have suggested that a poor understanding of the physical world and intuitive thinking styles correlate with an acceptance of paranormal and religious explanations over scientific explanations (Lindeman and SvedholmHäkkinen 2016). The process skills involved in science have been defined in many different ways, including scientific process skills (OECD 1999), procedural skills (e.g., Gott and Duggan 1994), experimental and investigative science (National Curriculum; DOE 1995), habits of mind (AAAS 1993), scientific inquiry abilities (National Academy of Sciences 1994), scientific reasoning skills (Lawson et al. 2000), or critical thinking skills (Bransford et al. 2000; NSF 2000). In addition, diverse ways of measuring these skills have been developed (e.g., the Cognitive Reflection Test, Frederick 2005; the Test of Scientific 
Literacy Skills, Gormally et al. 2012; the Watson-Glaser Critical Thinking Appraisal, Watson and Glaser 1991; the Assessment of Critical Thinking Ability, White et al. 2011; the Science Process Skills Test, Enger and Yager 1998; The Constructive Inquiry Science Reasoning Test, Weld et al. 2011; the Test of Logical Thinking, Tobin and Capie 1981; the Science Process Skills Test, Molitor and Goerge 1976; the Objective Referenced Evaluation in Science, Shaw 1983). In this study, we used the LCTSR, a measure of formal operational reasoning skills including proportional reasoning, identifying and controlling variables, probabilistic reasoning, correlational reasoning, and hypothetico-deductive reasoning. Thus, our conclusions are limited to this specific aspect of scientific reasoning ability. Perhaps there are other issues related to critical reasoning or processing, factors not measured by our instrument, that may cause an individual to reject evolution. More research into other complicating factors in acceptance for religious individuals is certainly warranted.

However, the conclusion that can be drawn is that scientific reasoning, as measured by formal operational skills appears not to be a predictive factor of acceptance of evolution among religious individuals. Likewise, the acceptance of evolution is not indicative of high scientific reasoning ability among religious individuals. These results may differ amongst areligious individuals. However, these data were not included in the present study, which focused only on religiously affiliated individuals. While religious views do appear to encumber evolution acceptance (as evidenced by the negative relationship between religiosity and evolution acceptance), our data indicate that it is not due to a lack of scientific reasoning ability among religious individuals.

\section{Conclusion}

A review of commonly used laboratory manuals designed for introductory biology courses (e.g., Lawson 1994; Mader 2007; Perry et al. 2009), shows that it is common practice to show students the evidence of evolution (e.g., fossils, diversification of species over long periods of time, emergence of new species and extinction of others) and encourage them to weigh this evidence, sometimes in contrast with a special creationist hypothesis (i.e., that all creatures were created in their present form from the beginning), in an effort to invoke scientific reasoning. A potential pedagogical rationale (see Lawson and Worsnop 1992) is that when instructors show students scientific data-and if the students use sound scientific reasoning-the logical conclusion would be to reject non-scientific views (e.g., special creation, young earth) in favor of evolutionary theory. This approach is in line with recent research suggesting that the rise in scientific understanding and scientific education has caused a decline in religiosity in the developed world (Barber 2011; Stavrova et al. 2016). However, given the results of the current study, this approach (i.e., appealing to scientific evidence) may do little to sway religious student acceptance of evolution. Recent research suggests that the previously supported relationship between analytic thinking and a disbelief in God (Gervais and Norenzayan 2012; Lynn et al. 2009; Norenzayan and Gervais 2013; Nyborg 2009; Pennycook et al. 2012; Shenhav et al. 2012; Zuckerman et al. 2013) may be mitigated by social and emotional cognition (Jack et al. 2016), a factor not easily addressed in a science classroom. In other words, new approaches to overcome the barriers to acceptance of evolution outside the approaches of simply presenting the data are needed. Some studies on alternative pedagogical approaches have shown some promise. By addressing religious conflict directly in the classroom and allowing students the time to consider and discuss the issues, researchers have shown that they can increase acceptance of evolution significantly amongst religious students (Manwaring et al. 2015) and decrease perceived conflict between evolution and religion (Barnes et al. 2017). Certainly, more work should be done in this area.

\section{Additional file}

Additional file 1: Instruments S1. Additional instruments. instruments created for this study.

\section{Authors' contributions}

Authors contributing to research design include KFM, JLJ, RAG, SMB. Authors contributing to data analysis include KFM, JLJ, RRS, RSD, SMB. Authors contributing to interpretation and manuscript preparation include KFM, JLJ, RAG, RRS, RSD, SMB. All authors read and approved the final manuscript.

\section{Author details}

1 Department of Biology, 4102 LSB, Brigham Young University, Provo, UT 84602, USA. ${ }^{2}$ Department of Instructional Psychology \& Technology, 150 MCKB, Brigham Young University, Provo, UT 84602, USA.

\section{Acknowledgements}

The authors would like to thank the Society for the Advancement of Biology Education Research (SABER) and the Biology Leadership Community (BLC) for their valuable feedback on this project. This support was funded by an internal institutional grant.

\section{Competing interests}

The authors declare that they have no competing interests.

Availability of data and materials

All data will be available and deposited on DRYAD for further exploration (upon acceptance).

\section{Ethics approval and consent to participate}

Permission for human subjects use was approved by the authors' institutional review board under the approval X110455. Permission was obtained from all participants. 


\section{Funding}

Funding for this work was provided by an internal institutional grant referred to as the David O. McKay Grant

\section{Publisher's Note}

Springer Nature remains neutral with regard to jurisdictional claims in published maps and institutional affiliations.

Received: 1 August 2017 Accepted: 13 March 2018

Published online: 17 March 2018

\section{References}

Alters BJ, Alters SM. Defending evolution: a guide to the evolution/creation controversy. Int J Sci Educ. 2001;33:2559-85.

American Association for the Advancement of Science. Benchmarks for scientific literacy. New York: Oxford University Press; 1993.

Anderson RD. Teaching the theory of evolution in social, intellectual, and pedagogical context. Sci Educ. 2007:91:664-77.

Andersson B, Wallin A. On developing content-oriented theories taking biological evolution as an example. Int J Sci Educ. 2006;28:673-95.

Bao L, Cai T, Koenig K, Fang K, Han J, Wang J, Wu N. Learning and scientific reasoning. Science. 2009:323:586-7.

Barber N. A cross-national test of the uncertainty hypothesis of religious belief. Cross-Cultural Research. 2011:45:318-33.

Barnes ME, Elser J, Brownell SE. Impact of a short evolution module on students' perceived conflict between religion and evolution. Am Biol Teach. 2017:79:104-11.

Barnes RM, Keilholtz LE, Alberstadt AL. Creationism and evolution beliefs among college students. Skeptic. 2009:14:13-6.

Branch G, Scott EC, Rosenau J. Dispatches from the evolution wars: shifting tactics and expanding battlefields. Annu Rev Genomics Hum Genet. 2010;11:317-38.

Bransford JD, Brown AL, Cocking RR (eds). How people learn. Brain, mind, experience, and school. Washington, D.C.: National Academic Press; 2000.

Carmel JH, Yezierski EJ. Are we keeping the promise? Investigation of students' critical thinking growth. J Coll Sci Teach. 2013;42:71-81.

Cornwall M, Albrecht SL, Cunningham PH, Pitcher BL. The dimensions of religiosity: a conceptual model with an empirical test. Rev Relig Res. 1986;1986:226-44.

Coyne JA. Science, religion, and society: the problem of evolution in America. Evolution. 2012;66:2654-63.

Darwin CR. On the origin of species by means of natural selection, or the preservation of favoured races in the struggle for life. London: John Murray; 1859.

Daeschler EB, Shubin NH, Jenkins FA Jr. A devonian tetrapod-like fish and the evolution of the tetrapod body plan. Nature. 2006:440:757-63.

Deniz H, Donnelly LA, Yilmaz I. Exploring the factors related to acceptance of evolutionary theory among Turkish preservice biology teachers: toward a more informative conceptual ecology for biological evolution. J Res Sci Teach. 2008;45:420-43.

Department of Education. Science in the national curriculum 1995. London: HMSO; 1995.

Dobzhansky T. Nothing in biology makes sense except in the light of evolution. Am Biol Teach. 1973;35:125-9.

Dobzhansky T, Pavlovsky O. An experimental study of interaction between genetic drift and natural selection. Evolution. 1957;11:311-9.

Drees WB. Science and the religions of the world. Zygon ${ }^{\circledR} 2012: 47(3): 477-80$

Enger SK, Yager RE, editors. lowa assessment handbook. lowa City: Science Education Center, The University of lowa; 1998.

Frederick S. Cognitive reflection and decision making. J Econ Perspect. 2005; 19:25-42.

Gallup. In U.S., Belief in creationist view of humans at new low. 2017. http:// news.gallup.com/poll/210956/belief-creationist-view-humans-new-low. aspx. Accessed 1 Dec 2017.

Gerber BL, Cavallo AM, Marek EA. Relationships among informal learning environments, teaching procedures and scientific reasoning ability. Int J Sci Educ. 1996;23:535-49.
Germann PJ. Testing a model of science process skills acquisition- an interaction with parents' education, preferred language, gender, science attitude, cognitive-development, academic ability, and biology knowledge. J Res Sci Teach. 1994;31:749-83.

Gervais WM, Norenzayan A. Analytic thinking promotes religious disbelief. Science. 2012;336:493-6.

Gormally C, Brickman P, Lutz M. Developing a test of scientific literacy skills (TOSLS): measuring undergraduates' evaluation of scientific information and arguments. CBE Life Sci Educ. 2012:11:364-77.

Gott R, Duggan S. Investigate work in science curriculum. Buckingham: Open University Press; 1994.

Grant PR, Grant BR. Unpredictable evolution in a 30-year study of Darwin's Finches. Science. 2002;296:707-11.

Haldane JBS. The cost of natural selection. J Genet. 1957;55:511-24.

Heddy BC, Nadelson LS. The variables related to public acceptance of evolution in the United States. Evol Educ Outreach. 2013;6:3.

Hokayem H, BouJaoude S. College students' perceptions of the theory of evolution. J Res Sci Teach. 2008:45:395-419.

Jack Al, Friedman JP, Boyatzis RE, Taylor SN. Why do you believe in God? Relationships between religious belief, analytic thinking, mentalizing and moral concern. PLoS ONE. 2016;11:e0149989. https://doi.org/10.1371/ journal.pone.0149989.

Jensen JL, Neeley S, Hatch JB, Piorczynski T. Learning scientific reasoning skills may be key to retention in science, technology, engineering, and mathematics. J Coll Stud Ret. 2015. https://doi.org/10.1177/1521025115611616.

Johnson MA, Lawson AE. What are the relative effects of reasoning ability and prior knowledge on biology achievement in expository and inquiry classes? J Res Sci Teach. 1998;35:89-103.

Kahan DM, Stanovich KE. Rationality and belief in human evolution. Annenberg public policy center working paper no. 5. 2016. https://ssrn.com/ abstract $=2838668$. Accessed 30 June 2017.

Lawson AE. Development and validation of the classroom test of formal reasoning. J Res Sci Teach. 1978;15:11-24.

Lawson AE. The nature of advanced reasoning and science instruction. J Res Sci Teach. 1982;19:743-60.

Lawson AE. Investigation 36: what changes have occurred in organisms through time? In: Lawson AE, editor. Biology: a critical thinking approach, teacher's guide. Menlo Park: Addison-Wesley Publishing Company Inc; 1994. p. 222-36.

Lawson AE, Alkhoury S, Benford R, Clark BR, Falconer KA. What kinds of scientific concepts exist? Concept construction and intellectual development in college biology. J Res Sci Teach. 2000;37:996-1018.

Lawson AE, Banks DL, Logvin M. Self-efficacy, reasoning ability, and achievement in college biology. J Res Sci Teach. 2007:44:706-24.

Lawson AE, Thompson LD. Formal reasoning ability and misconceptions concerning genetics and natural selection. J Res Sci Teach. 1988;25:733-46.

Lawson AE, Weser J. The rejection of nonscientific beliefs about life: effects of instruction and reasoning skills. J Res Sci Teach. 1990;27:589-606.

Lawson AE, Worsnop WA. Learning about evolution and rejecting a belief in special creation: effects of reflective reasoning skill, prior knowledge, prior belief and religious commitment. J Res Sci Teach. 1992:29:143-66.

Lin PC. A study of Piagetian cognitive-development and psychometric IQ in junior and senior high-school students. ACTA Psychologica Taiwanica. 1980;22:33-49.

Lindeman M, Svedholm-Häkkinen AM. Does poor understanding of physical world predict religious and paranormal beliefs? Appl Cogn Psychol. 2016;30(5):736-42.

Lynn R, Harvey J, Nyborg H. Average intelligence predicts atheism rates across 137 nations. Intelligence. 2009;37:11-5.

Mader SS. Evidences of evolution. In: Mader SS, editor. Biology laboratory manual. 9th ed. Columbus: McGraw-Hill Companies Inc; 2007. p. 145-60.

Manwaring KF, Jensen JL, Gill RA, Bybee SM. Influencing highly religious undergraduate perceptions of evolution: mormons as a case study. Evol Educ Outreach. 2015:8:1-12.

Mayr E. The growth of biological thought: diversity, evolution and inheritance. Cambridge: Belknap Press; 1982

Miller T. U.S. religious landscape survey: religious beliefs and practices: diverse and politically relevant. The pew form: on religion \& public life. Washington: 2008. p. 95-97.

Miller JD, Scott EC, Okamoto S. Public acceptance of evolution. Science. 2006:313:765-6. 
Molitor L, Goerge K. Development of a test of science process skills. J Res Sci Teach. 1976;13(5):405-12

Moore R, Brooks C, Cotner S. The relation of high school biology courses and students' religious beliefs to college students' knowledge of evolution. Am Biol Teach. 2011;73:222-6.

Muthén LK, Muthén BO. Mplus user's guide, 6th ed. Los Angeles: Muthén \& Muthén; 1998-2010.

Nadelson LS, Sinatra GM. Shifting acceptance of evolution: promising evidence of the influence of the "understanding evolution" website. Res. 2010;23:13-29.

National Academy of Sciences. National science education standards. Washington, DC: National Academy of Sciences; 1994.

National Science Foundation. Foundations volume 2: A monograph for professionals in science, mathematics, and technology education. 2000. http:// www.nsf.gov/pubs/2000/nsf99148/start.htm. Retrieved 17 July 2015.

Nehm RH, Schonfeld IS. Does increasing biology teacher knowledge of evolution and the nature of science lead to greater preference for the teaching of evolution in schools? J Sci Teacher Educ. 2007;18:699-723.

Niaz M. Correlates of formals operational reasoning-a Neo-Piagetian analysis. J Res Sci Teach. 1991;28:19-40.

Norenzayan A, Gervais WM. The origins of religious disbelief. Trends Cogn Sci. 2013;17:20-5

Nyborg $\mathrm{H}$. The intelligence-religiosity nexus: a representative study of white adolescent Americans. Intelligence. 2009;37:81-93.

OECD. Performance indicators for student achievement (PISA). Science Fraemwork. Paris: OECD; 1999.

Ostrom JH. Archaeopteryx and the origin of birds. Biol J Lin Soc. 1976;8:91-182.

Pennycook G, Cheyne JA, Seli P, Koehler DJ, Fugelsang JA. Analytic cognitive style predicts religious and paranormal belief. Cognition. 2012;123:335-46

Perry JW, Morton D, Perry JB. Evidences of evolution. In: Perry JW, Morton D, Perry JB, editors. Laboratory manual for majors general biology. Belmont: Brooks/Cole CENGAGE Learning; 2009. p. 183-96.

Pew. U.S. Religious landscape survey, June 2008. Pew Research Center, Washington, DC. 2008. http://www.pewforum.org/files/2013/05/reportreligious-landscape-study-full.pdf. Accessed 30 June 2017.

Pew. Public and scientists' views on science and society. Pew Research Center, Washington, DC. 2015. http://www.pewinternet.org/2015/01/29/publicand-scientists-views-on-science-and-society/pi_2015-01-29_scienceand-society-03-08/. Accessed 30 June 2017.

Plutzer E, Berkman M. The polls-trends: evolution, creationism, and the teaching of human origins in schools. Public Opin Q. 2008;72:540-53.

Provine WB. The origins of theoretical population genetics. Chicago: University of Chicago Press; 1971.

28 Questions to help buyers of online samples. https://www.esomar.org/ knowledge-and-standards/research-resources/28-questions-on-onlinesampling.php. Accessed 9 Jun 2017.
Religious landscape study. http://www.pewforum.org/religious-landscapestudy/. Accessed 9 Jun 2017.

Rissler LJ, Duncan SI, Caruso NM. The relative importance of religion and education on university students' views of evolution in the Deep South and state science standards across the United States. Evol Educ Outreach. 2014;7:24.

Rutledge ML, Sadler KC. Reliability of the measure of acceptance of the theory of evolution (MATE) instrument with university students. Am Biol Teach. 2007:69:332-5.

Scott EC. Evolution vs. creationism: an introduction. Berkeley: University of California Press; 2005

Scott EC. Antievolution and creationism in the United States. Annu Rev Anthropol. 1997;26:263-89.

Sethi S, Seligman MEP. Optimism and fundamentalism. Psychol Sci. 1993:4:256-9.

Shaw T. The effect of a process-oriented science curriculum upon problem solving ability. Sci Educ. 1983;67(5):615-23.

She $\mathrm{H}$, Liao Y. Bridging scientific reasoning and conceptual change through adaptive web-based learning. Journal of Research in Science Teaching. 2010:47:91-119.

Shemesh M. Gender-related differences in reasoning skills and learning interests of junior-high-school students. J Res Sci Teach. 1990;31:749-83.

Shenhav A, Rand DG, Greene JD. Divine intuition: cognitive style influences belief in God. J Exp Psychol. 2012;141:423-8.

Stavrova O, Ehlebracht D, Fetchenhauer D. Belief in scientific-technological progress and life satisfaction: the role of personal control. Personal Individ Differ. 2016:96:227-36.

Theobald DL. A formal test of the theory of universal common ancestry. Nature. 2010:465:219-23.

Tobin K, Capie W. The development and validation of a group test of logical thinking. Educ Psychol Measur. 1981:41(2):413-24

Village A, Baker S. Rejection of Darwinian evolution among churchgoers in England: the effects of psychological type. J Sci Study Relig. 2013;52(3):557-72.

Watson G, Glaser EM. Watson-Glaser critical thinking appraisal manual. London: Psychological Corporation; 1991.

Weld J, Stier M, McNew-Birren J. The development of a novel measure of scientific reasoning growth among college freshmen: the constructive inquiry science reasoning skills test. J Res Sci Teach. 2011;40(4):101-7.

White B, Stains M, Escriu-Sune M, Medaglia E, Rostamnjad L, Chinn C, Sevian H. A novel instrument for assessing students' critical thinking abilities. J Res Sci Teach. 2011:40(5):102-7.

Zimmerman C. The development of scientific reasoning skills. Dev Rev. 2000;20:99-149.

Zuckerman M, Silberman J, Hall JA. The relation between intelligence and religiosity a meta-analysis and some proposed explanations. Personal Soc Psychol Rev. 2013. https://doi.org/10.1177/1088868313497266.

\section{Submit your manuscript to a SpringerOpen ${ }^{\circ}$ journal and benefit from:}

- Convenient online submission

- Rigorous peer review

- Open access: articles freely available online

- High visibility within the field

Retaining the copyright to your article

Submit your next manuscript at springeropen.com 